\title{
REFLEXÕES SOBRE A DANÇA E A EDUCAÇÃO A DISTÂNCIA: UMA PERSPECTIVA INCLUSIVA NA CULTURA DIGITAL
}

\section{REFLECTIONS ABOUT THE DANCE AND DISTANCE EDUCATION: AN INCLUSIVE PERSPECTIVE IN THE DIGITAL CULTURE}

\author{
DOI: http://dx.doi.org/10.5965/1984317815022019142 \\ Cristiane do Rocio Wosniak \\ Universidade Estadual do Paraná / Universidade Federal do Paraná \\ cristiane.wosniak@unespar.edu.br \\ Everson Luiz Oliveira Motta \\ Pontifícia Universidade Católica de São Paulo / UniCesumar \\ soneve@gmail.com
}

\section{RESUMO}

Este artigo tem o objetivo de refletir sobre as possibilidades de uma educação tecnológica e híbrida como contributo para a formação de artistas-docentes no âmbito das licenciaturas em dança no Brasil. O foco da investigação recai sobre a proposta de educação a distância (EaD), que rompe o paradigma da aprendizagem e da prática da dança unicamente de forma co(rpo)presencial e artesanal. A partir da verificação do estado da arte de nosso objeto de pesquisa no Brasil, constatamos a inexistência de publicações dedicadas ao tema dança e educação a distância. Assim sendo, propomos uma ampla discussão, ancorados na metodologia de revisão bibliográfica narrativa, sobre a possibilidade desafiadora da educação a distância, com seus meios de aprendizagem e instrumentos comunicacionais, na relativização de espaços geográficos, nas aproximações de conhecimentos acerca da linguagem da arte/ dança e na otimização do tempo de acesso a um conjunto de informações, mediadas pelas plataformas digitais. Concluímos que a EaD torna-se um elemento imprescindível para repensarmos/avaliarmos nossas práticas educacionais colaborativas no âmbito da formação de professores de dança, que deverão atuar nos novos contextos educacionais contemporâneos, permeados por uma vasta rede de relações que concebem o corpo e a comunicação ubíqua em suas extensões tecnológicas multifacetadas.

Palavras-chave: Educação a distância. Tecnologia educacional. Formação docente. Alternativas de aprendizagem.

\begin{abstract}
This reflective article has teh purpose to reflect about the potential of technological and blended education to contribute to the training of artists-teachers in dance degree programs in Brazil. Our research is focused on the modality of distance education (DE) that breaks the conventional paradigm of dance learning and practice only in a face-to-face and artisanal form. By surveying the state of the art of dance learning and practice, we have found a shortage of publications focused on the issue. Therefore, we propose, anchored in the literature review methodology, a broad discussion on the challenging potential of $D E$, with all its learning and communication tools, in relativizing of geographical spaces, in gathering knowledge about the language of art and dance, as well as in optimizing access time to a comprehensive set of information mediated by digital platforms. We conclude that $\mathrm{DE}$ is a key element in rethinking and evaluating our collaborative educational practices in the context of training dance teachers who shall act in new
\end{abstract}


contemporary educational settings permeated by a vast network of relations that conceive the body and ubiquitous communication in their multifaceted technological extensions.

Keywords: Distance education. Educational technology. Teacher training. Learning alternatives.

\section{INTRODUÇÃO}

A emergência da cultura digital e dos processos comunicacionais interativos na contemporaneidade têm transformado o modo como pensamos o sujeito e, no caso específico da educação, o sujeito da aprendizagem, alterando significativamente as formas sociais, culturais e educacionais. A Educação a Distância (EaD) como possibilidade de uma comunicação bilateral na relação professor-aluno como habitantes de diferentes espaços geográficos, permite que qualquer pessoa interessada participe de "um processo formativo virtual, independente de sua localização, tendo como base a construção de redes, bastando ter acesso a um computador ligado à internet e, no caso de ter critérios de seleção específicos, cumprilos" (CUNHA, 2016, p. 6).

A EaD, segundo Cunha (2016) tem a capacidade de agrupar diversos perfis de interesse e disponibilidade em um mesmo ambiente de estudo, permitindo identificar a diversidade exposta na sociedade contemporânea brasileira, "tornando-se este o seu maior desafio e, ao mesmo tempo, o seu grande diferencial como processo formativo na diversidade" (CUNHA, 2016, p. 9).

A dança, cuja matriz educacional se fundamenta sobre a tradição da co(rpo)presença1, estaria disponível e aberta para admitir a suposta 'invasão' das metodologias de ensino a distância e dos corpos comunicativos e ubíquos a 'macular' o território dos processos de ensino-aprendizagem regidos, na contemporaneidade, pela (i)materialidade do virtual?

A educação de nível superior - especificamente a licenciatura em dança, responsável pela formação dos profissionais da educação em artes/dança - não se

1 Com este neologismo, proposto pelos autores da presente investigação, entende-se a materialidade presencial dos professores em relação aos alunos/dançarinos - presentes no espaço-tempo da sala/ estúdio de dança enquanto estes últimos aprendem as lições, gestos e movimentos dançantes. 
encontraria em um impasse diante de tantas mudanças radicais na sociedade tecnológica do século XXI? Neste contexto, Santaella (2003), considera que já está se tornando lugar comum a afirmação de que as novas tecnologias da informação e da comunicação estão transformando não apenas as formas de entretenimento e lazer, mas potencialmente todas as esferas da sociedade: "trabalho [...] gerenciamento político, atividades militares, policiais, comunicação e educação (aprendizagem à distância) [grifo nosso]" (SANTAELLA, 2003, p. 209).

Neste artigo, refletimos sobre os (per)cursos da formação de professores e estudantes de artes/dança no Brasil, considerando o impacto da educação e dos processos renovados de ensino-aprendizagem em um contexto tecnológico.

Não se trata aqui, como afirma Menicacci (2009, p. 101), de "agitar as bandeiras em nome de uma religião do processo eletrônico/digital", nem tampouco de dar respostas definitivas às discussões apaixonadas e polêmicas entre grupos favoráveis ou contrários ao uso das novas tecnologias de aprendizagem no campo do ensino das artes do corpo.

Acreditamos, entretanto, que os processos de organização dos currículos nas diferentes graduações em dança no Brasil, as metodologias a serem dispensadas para o acesso aos saberes inerentes ao exercício do magistério, além dos tempos e dos espaços alternativos da aprendizagem precisam ser discutidos e, talvez, revistos, frente à visível e limitada oferta numérica de graduações em dança no país.

Atualmente, segundo o site do Instituto Nacional de Estudos e Pesquisas Educacionais (INEP) e segundo Wosniak (2017) e Silva (2016), existem apenas 42 cursos de graduação em dança: 16 instituições federais, 5 estaduais e 9 particulares oferecem 28 cursos de licenciatura e 14 de bacharelado, totalizando 42 cursos, cuja abordagem pedagógica predominante, nestas instituições de ensino superior, é centrada na modalidade co(rpo)presencial. 
Nesta investigação, apresentamos uma proposta de educação tecnológica e híbrida na modalidade a distância e/ou semipresencial - imbuída de uma perspectiva inclusiva de sociedade, trazendo para a discussão os conceitos de educação por meio de uma comunicação ubíqua e colaborativa.

\section{ASPECTOS METODOLÓGICOS DA INVESTIGAÇÃO}

Adotamos uma metodologia de pesquisa pautada por uma meticulosa Revisão de Literatura Narrativa (RLN). A opção por este tipo de estratégia metodológica nos possibilita, como afirma Martins (2001), o acesso à produção de conhecimento de autores que já se debruçaram sobre o assunto e, assim, partimos em consulta a referenciais teóricos constantes em documentos legais, sites, livros, periódicos, artigos indexados e base de dados. A condensação de conhecimentos a partir de temas centrais à investigação permite localizar possíveis espaços de pesquisa ainda inexplorados. De acordo com a (RLN) não é necessária a utilização de critérios explícitos e sistemáticos para a busca e análise crítica da literatura aqui recortada. Em nossa busca pelos trabalhos já desenvolvidos, estamos cientes de que não esgotamos as diversas fontes de informações, visto que não pretendemos utilizar estratégias de busca sofisticadas e/ou exaustivas.

Partimos das seguintes questões norteadoras: de que forma e com que meios uma educação tecnológica e híbrida poderia contribuir para a formação de artistasdocentes no âmbito das licenciaturas em dança no Brasil? Um possível proposta de educação a distância (EaD), que rompe o paradigma da aprendizagem e da prática da dança unicamente de forma co(rpo)presencial e artesanal já estaria sendo pesquisada no Brasil?

$\mathrm{Na}$ tentativa de refletir sobre estas questões, acessamos as bases de dados na Biblioteca SciELO - Scientific Electronic Library Online e sites de busca por elementos descritores como EaD; Ensino e Aprendizagem em Dança; Educação ubíqua; Ensino semi-presencial; Tecnologia e(m) educação; Formação do artista-docente. Por meio de 
buscas avançadas realizadas em novembro e dezembro de 2018 , utilizando-se os termos delimitadores de pesquisa, empreendemos quatro sessões de atividades de pesquisa, identificação, fichamento de estudos, discussões e reflexões analíticas.

Para este estudo, também utilizamos como referenciais balizadores do tema tecnologia e $(m)$ educação os seguintes autores: Bates (2017), Grinspun (2007), Kenski (2012; 2013), Marques (2007) Peña, Alves e Peppe (2003), Santaella (2003; 2013), Mattar (2011; 2013; 2017), Morán (2015), Silva (2016) e Tardif (2014).

\section{A EDUCAÇÃO A DISTÂNCIA E A LICENCIATURA EM DANÇA NO BRASIL}

A EaD no Brasil se fortalece ano após ano, como uma das principais contribuições dos avanços das tecnologias para a educação. Sendo assim, nas palavras de Mattar (2011, p. 3), trata-se de "uma modalidade de educação, planejada por docentes ou instituições, em que professores e alunos estão separados espacialmente" e, por meio de um sistema de ensino colaborativo, fazem uso de diversas tecnologias de comunicação.

A EaD, em uma rápida visada sobre sua construção histórica, acentua o seu início a partir de um modelo de aprendizagem na/da era analógica, perpassando os folhetos de jornal na bancada dos correios, do rádio e da televisão. Tais formatos comunicacionais nos demonstram a nascente de um modelo que só seria regulamentado após a Lei de Diretrizes e Bases da Educação Nacional (LDBEN), de 1996.

Com o advento da internet alteram-se, definitivamente, os paradigmas e os conceitos na/da educação, o que deflagrou a sistematização e a difusão do processo de ensino-aprendizagem mediado à distância. A EaD surge, inicialmente, com um discurso alinhado à ampliação do acesso à escola, a fim de superar uma lacuna no processo educacional inclusivo, sendo vista por inúmeras instituições também como uma possibilidade econômica e viável de ensino. Não obstante, estaria o pensamento 
conceitual da modalidade de EaD em dança gravitando em uma perspectiva de substituição gradual do ensino co(rpo)presencial?

Menicacci (2009), menciona que os receios e temores da derrocada de um meio de comunicação ou ferramenta de expressão, em vias do surgimento de novos mecanismos, é infundada. Nas palavras do autor:

não falamos menos e não nos comunicamos menos depois da invenção da escrita, mas esta permitiu diversificar a conservação, a divulgação, etc. A fotografia não substituiu a pintura, mas permitiu que os pintores não fossem os únicos produtores de imagens. O cinema não substituiu o teatro e acabou tornando-se uma arte específica. $O$ desenvolvimento da telefonia não desencadeou uma diminuição dos contatos pessoais/ visuais e uma recessão dos transportes. Ao contrário, o desenvolvimento da telefonia,[...], e recentemente, da telefonia móvel, é contemporâneo de uma grande democratização dos transportes. $\mathrm{Na}$ verdade, não nos confrontamos com a ameaça do desaparecimento de um meio de comunicação e de criação, mas com o aumento de universos de escolha. Os sistemas não se substituem, mas se tornam mais complexos e se diversificam ao nos oferecer acesso a novos planos de existência [grifo nosso]. (MENICACCI, 2009, p. 102).

A partir da Lei de Diretrizes e Bases da Educação Nacional, de 20 de dezembro de 1996, o modelo de ensino à distância desponta como um aumento de universos de escolha, representado pelo decreto de $\mathrm{N}^{\circ}$ 9.057/17 que a regula atualmente. Consta neste mesmo documento apontamentos nos quais se sugere uma flexibilização para a criação de polos de apoio, o credenciamento de instituições e cursos, além do incentivo à tecnologia, favorecendo, assim, o seu amadurecimento como modalidade educativa. Ao se incluir neste contexto o termo semipresencial, nas palavras de Morán (2015), há uma separação do que acontece à distância e o que acontece no sistema presencial ou semipresencial. É importante salientar que, em alguns documentos brasileiros oficiais, como a Portaria do MEC $n^{\circ} 4.059 / 2004$ em seu artigo 10, podemos encontrar o termo semipresencial significando as atividades didáticas ou "unidades de ensino e aprendizagem centrados na autoaprendizagem e com a mediação de recursos didáticos organizados em diferentes suportes de informação que utilizem tecnologias de comunicação remota" (BRASIL, 2004). 
De acordo com o artigo 10 da Lei 4.059/2004: "§2० - Poderão ser ofertadas as disciplinas no caput, integral ou parcialmente, desde que esta oferta não ultrapasse $20 \%$ (vinte por cento) da carga horária total do curso." Em outras palavras, a oferta das disciplinas e cursos pode ser exequível de forma parcial ou integral, mas desde que não ultrapasse as porcentagens mencionadas.

Uma solicitação que se faz neste processo é que as avaliações das disciplinas ofertadas na modalidade semipresencial deverão ser realizadas presencialmente, tendo o auxílio de tutores treinados nestes encontros. Nesse sentido, Machado (2018) conclui que o sistema de ensino semipresencial é considerado uma derivação da EaD, "mesclando tempos presenciais e tempos à distância. Não há nos dispositivos legais um padrão definido para a separação desses tempos, deixando assim a livre interpretação" (MACHADO, 2018, p. 46).

Mattar (2017), em seu texto Metodologias Ativas: para educação presencial, Blended e a distância, menciona a designação atual desse ensino semipresencial e mediado por tecnologias híbridas e misturadas como 'Ensino Híbrido'. As fronteiras dos mecanismos de ensino e aprendizagem $\mathrm{e}(\mathrm{m})$ seus instrumentos e ferramentas tecnológicas e pedagógicas são borradas neste sistema.

O Ensino Híbrido coloca em primeiro lugar o(a) estudante como o centro do processo pedagógico, tal como postulam Tardif (2014) e Marques (2007), como protagonista de suas escolhas, adquirindo maior autonomia em sua aprendizagem, cabendo ao professor/tutor o papel de problematizar, incentivar, mediar as melhores escolhas para os discentes em seus textos e contextos.

$\mathrm{Na}$ atualidade, portanto, urge repensar os modelos pedagógicos para o ensino da dança nos cursos superiores, propondo ou intensificando ações de mediação tecnológica, como apontam Kenski (2012) e Fava (2016), para o ensino formal. Nesse sentido, trabalhar os conteúdos pedagógicos em plataformas online e estar simbioticamente ocupando espaços de forma ubíqua poderia ser uma justificativa para a implantação da EaD de forma semipresencial nos cursos de graduação em dança, sobretudo nas licenciaturas voltadas para a formação de profissionais da educação em 
artes/dança. Trata-se da modalidade blended/híbrida, como mencionamos anteriormente, não descartando nenhuma possibilidade de aprendizagem, estendendo o espaço físico da sala de aula para espaços alternativos mediados pela tela do computador.

Para Morán (2015):

O ensinar e aprender acontecem numa interligação simbiótica, profunda, constante entre o que chamamos mundo físico e mundo digital. Não são dois mundos ou espaços, mas um espaço estendido, uma sala de aula ampliada, que se mescla, hibridiza constantemente. Por isso a educação formal é cada vez mais blended, misturada, híbrida, porque não acontece só no espaço físico da sala de aula, mas nos múltiplos espaços do cotidiano, que incluem os digitais (MORÁN, 2015, p. 16).

Entretanto, para dar conta das novas práticas de ensino-aprendizagem em educação online, utilizando-se de plataformas da web, redes sociais e dispositivos móveis, Mattar (2013) admite que seriam necessárias novas estratégias pedagógicas que levem em conta a interação e a comunicação ubíqua em ambientes digitais/ virtuais. Os cursos de licenciatura em dança no Brasil estariam atentos e abertos aos desafios que despontam no panorama atual? Poderiam os espaços físicos da sala de aula e do estúdio de dança no/do ensino superior tornarem-se um espaço estendido complementar?

A partir da observação da Lei 13.278/2016 que alterou o art. 26 da LDBEN: "As artes visuais, a dança, a música e o teatro são as linguagens que constituirão o componente curricular de que trata o §2॰ deste artigo", constituindo-se assim, componente curricular obrigatório da Educação Básica, iniciamos este tópico de reflexão com uma pergunta provocativa e inquietante: o número de instituições de ensino superior em Dança no Brasil é suficiente e forma profissionais da educação/ professores capacitados, em uma média adequada, anualmente, para abarcar a realidade numérica e a demanda profissional, no ensino formal da rede municipal, estadual e privada? 
Como destaca Wosniak (2017), embora a implantação de graduações em Dança no Brasil se encontre em regime de expansão nos últimos dez anos e a opção pelas Licenciaturas em Dança seja a tônica predominante, o número de instituições públicas ou privadas, que ofertam seus cursos de forma estritamente presencial, ainda é inexpressivo e dificilmente poderá dar conta da demanda necessária ao preenchimento de vagas para a atuação como professor de artes/dança no ensino formal em território nacional.

Neste momento de nossa reflexão, não podemos deixar de mencionar a atual implantação da reforma no ensino no Brasil e o impacto sobre a atuação dos profissionais da educação em artes/dança neste contexto, visto que a Base Nacional Comum Curricular (BNCC), que estabelece os conhecimentos e as habilidades essenciais e que fazem parte dos currículos de todas as escolas, públicas e privadas, de Ensino Médio no Brasil já foi homologada.

Sublinhamos que a história dos cursos superiores em Dança no país tem início somente em 1956 e, segundo Silva (2016), a Escola de Dança da Universidade Federal da Bahia foi, durante vinte e nove anos, a única possibilidade de formação em dança no nível superior. Wosniak (2017), acentua que foi somente na década de 1980 que outros três cursos superiores de dança foram implantados no país. Em Curitiba, a Pontifícia Universidade Católica do Paraná, em convênio com a Fundação Teatro Guaíra (1984), criava o segundo curso no Brasil - o Bacharelado e Licenciatura em Dança, que desde 2011 encontra-se vinculado à Universidade Estadual do Paraná, campus de Curitiba II/Faculdade de Artes do Paraná - com dupla habilitação. No Rio de Janeiro, no mesmo ano, um pouco mais tarde, a UniverCidade (1984) criava a Licenciatura em Dança, e, em Campinas, na Unicamp (1986) a dupla habilitação também era a opção da graduação. Devemos destacar esta dupla habilitação simultânea, ainda em voga em algumas instituições de ensino superior no país - artista e docente - ou mais precisamente, bacharelado e licenciatura, atuando 
concomitantemente na formação do que se entende, na contemporaneidade, por artista-docente ${ }^{2}$.

As Diretrizes Curriculares Nacionais (DCNs) para os cursos de graduação em Dança do CNE, aprovadas em março de 2004, compreendem toda a organização do projeto pedagógico, o perfil do egresso, as competências e habilidades, os componentes curriculares, o estágio curricular supervisionado, as atividades complementares, o sistema de avaliação, a confecção do trabalho de conclusão de curso, o projeto de iniciação científica, o programa de iniciação à docência, quando houver, e outros aspectos relevantes do projeto pedagógico total, conforme as linhas e vocações contextuais específicas de cada curso em cada região brasileira.

As DCNs, aprovadas em 2004, indicam as habilidades a serem desenvolvidas nos profissionais egressos dos cursos de graduação em dança no Brasil. Destacamos as seguintes: a) o domínio dos princípios cinesiológicos relativos à performance corporal; b) o domínio da linguagem corporal quanto à interpretação coreográfica nos aspectos técnicos e criativos; c) os desempenhos indispensáveis à identificação, descrição, compreensão, análise e articulação dos elementos da composição coreográfica, sendo capaz de exercer essas funções em conjunto com outros profissionais; d) o reconhecimento e a análise de estruturas metodológicas e domínios didáticos acerca do ensino da dança; e) o domínio de habilidades indispensáveis ao trabalho da dança do portador de necessidades especiais, proporcionando a todos a prática e o exercício dessa forma de arte como expressão de vida.

Segundo Motta (2018) e Silva (2016), a organização curricular desses cursos deve oferecer conteúdos básicos interligados a estudos relacionados com as artes cênicas, a música, a filosofia, as ciências da saúde, as ciências humanas, sociais e a psicologia; conteúdos específicos relacionados com a estética, a história das artes e da dança, as técnicas de criação artística e de expressão corporal, coreografia e

\footnotetext{
2 O termo 'artista-docente' foi cunhado por Isabel Marques em sua pesquisa/tese de doutorado defendida em 1996, na Faculdade de Educação da USP e intitulada Dança no contexto: uma proposta para a educação contemporânea.
} 
cinesiologia; conteúdos teórico-práticos, em estudos de domínio de técnicas e princípios informadores da expressão corporal e musical, espaços cênicos, artes plásticas e demais aspectos da produção em dança. Além disso, estão listados os componentes específicos para a licenciatura, tais como os conteúdos didáticos, metodológicos e de estágio supervisionado. Entre os eixos disciplinares teóricos, práticos, criativos e didáticos, os alunos e alunas devem perfazer um mínimo de 2.400 horas para o bacharelado e 2.800 horas para a licenciatura, sendo os limites mínimos para integralização três anos e meio ou quatro anos.

Com o objetivo de citar um modelo possível de pensamento educacional artístico para um currículo em curso de graduação, apresentamos o Curso de Bacharelado e Licenciatura em Dança da Universidade Estadual do Paraná, campus de Curitiba II/ Faculdade de Artes do Paraná, que, atento às novas demandas da sociedade, implantou, em 2017, sua proposta de alteração curricular. O Projeto Pedagógico de Curso (PPC, 2017), elaborado pelo Núcleo Docente Estruturante (NDE) está fundamentado na concepção de formação do artista-docente como um cidadão comprometido com possibilidades de atuação multidirecional, capaz de ampliar a inclusão social e o desenvolvimento humano. O referido PPC foi aprovado em dezembro de 2017 e implantado em 2018.

Tal reformulação curricular, perpassa o contexto de inserção do curso em uma Instituição de Ensino Superior pública e gratuita, cuja política de responsabilidade social se caracteriza pelo compromisso com valores como democracia, liberdade, justiça social, cidadania, educação, identidade, pluralidade e ética.

O curso evidencia, em sua concepção (PPC, 2017), a relevância social do estabelecimento de relações com uma realidade em movimento [grifo nosso], entendida como atividade humana que exige organicidade entre pensamento e ação, teoria e prática, profundamente imbricada na perspectiva emancipatória de educação. No campo pedagógico, o curso pretende assumir a abordagem de práxis educativa transformadora, com o objetivo de garantir a interdependência existente entre os processos de investigação, criação, ensino e aprendizagem para a construção do 
conhecimento. $\mathrm{O}$ documento ainda prevê, em sua redação, a perspectiva de criação e ensino da dança, a noção de validação da diferença dos corpos e danças, expandindo a ideia de formação 'para' múltiplas danças e corpos, como um saber constituído a priori, para adotar a concepção de formação 'com' múltiplos corpos e danças. Este entendimento de educação com/na diferença extrapola abordagens disciplinares de aprendizagem inclusiva e multicultural e implica na validação política de todos os corpos e suas danças, tanto nos procedimentos de ingresso no curso, como no desenvolvimento da matriz curricular que constitui, em sua abordagem metodológica investigativa, a base filosófica de uma concepção de formação artístico-pedagógica diversa e inclusiva.

A articulação artístico-pedagógica, assumida na concepção da estrutura curricular, evidencia as especificidades e complementariedades da Licenciatura e do Bacharelado em Dança apoiadas na noção sistêmica de complexidade de produção de conhecimento, implícita no abandono do entendimento cartesiano de linearidade de junção das partes com finalidade de conhecimento do todo, problematizando o binômio Arte-Educação. Tal organização curricular é reconhecida atualmente em nível nacional e internacional como a identidade do curso e tem colaborado para a transformação paradigmática de entendimentos sócio-políticos e culturais vinculados à separação entre o fazer-pensar, criar-ensinar, historicamente enraizados e ainda predominantes em alguns dos campos de atuação da dança.

Em relação aos demais modelos de graduação em dança existentes no país, Silva (2016), assume que os cursos de bacharelado enfatizam o desempenho prático e assim oferecem maior carga horária em disciplinas para desenvolver as habilidades técnicas e o desempenho interpretativo dos alunos. Essas habilidades, de acordo com os princípios de cada técnica, estão intrinsecamente ligadas a saberes específicos das dimensões e a sistemas organizacionais do corpo humano, ou seja, o sistema esquelético, o muscular, o proprioceptivo e, sobretudo, o cinesiológico. Por outro lado, o profissional que opta pela licenciatura, segundo a autora, "necessita ainda de mais 
conhecimento, uma vez que será responsável pela transmissão de habilidades técnicas e expressivas ao seu aluno." (SILVA, 2016, p. 33).

Depreende-se, do exposto, que o professor do/no curso superior não mais possui o papel de detentor absoluto dos saberes, mas está assumindo gradativamente o seu papel de orientador, tutor e/ou estimulador das qualidades singulares de cada discente.

Salienta Silva (2016, p. 34) que, nesta perspectiva, "cada aluno trará no seu corpo, no seu movimento e no seu repertório de informações os rastros da sua trajetória de vida, tornando-se o principal protagonista no binômio ensinoaprendizagem."

[...] nas novas abordagens pedagógicas para o ensino da dança, não é mais possível manter o modelo ultrapassado do espelhamento e da tentativa de cópia do professor pelo aluno, pois não se pode mais pensar o corpo do dançarino como mero instrumento para a dança. Deve-se pensar o corpo como motor fundamental da construção do pensamento em dança, o que poderá posteriormente ser expresso pelo movimento e pela criação artística. Nesse processo, na formação do aluno são plenamente respeitadas a sua formação, informação e história de vida [...]Dessa forma, o professor pode ensinar ao aluno não apenas um repertório de movimentos ou como funciona seu corpo, fatos históricos ou certa maneira de pensar a arte, mas principalmente ensiná-lo a acreditar na sua individualidade, a encontrar o caminho da sua potência criativa, que é possível inventar seus próprios passos na dança e na vida de artista, com base na sua identidade corporal e cultural. Esse caminho é então construído no espaço entre o aluno e o professor, tocado inicialmente a quatro mãos e, mais adiante, a muitas mãos e tantos corpos quantos forem aqueles dos trabalhos em grupo. Isso só é possível mediante a aplicação dos conteúdos relacionados do curso, entre as disciplinas práticas, teóricas e criativas, pois atualmente se busca uma interseção de todos esses saberes, que não mais são lecionados de forma estanque, como no modelo ultrapassado dos currículos antigos (SILVA, 2016, p. 34).

A partir do raciocínio aqui exposto, percebemos que os cursos de graduação/ licenciatura em dança parecem estar atentos às profundas transformações sociais, históricas, políticas e culturais do(no) país. Todavia, observamos que as reformulações curriculares destacadas no panorama nacional ainda estão restritas às mudanças de 
conteúdos e métodos de ensino-aprendizagem, enfatizando o protagonismo discente co(rpo)presencialmente no espaço físico da sala de aula institucional.

No próximo tópico, apontaremos algumas considerações sobre as possibilidades de extravasamento de fronteiras entre o espaço físico da sala de aula ou estúdio de dança em prol de um possível espaço comunicativo e ubíquo, mediado pelas tecnologias educacionais e descentralizadas pela modalidade de EaD.

\section{EaD EM DANÇA: APRENDER A DANÇAR AQUI, ALI E EM TODO O LUGAR}

A partir de Motta (2018), concebemos que o conceito de dança e o de corpo se modificaram ao longo da história das artes do corpo. Mais do que preceituar um ponto de vista teórico sobre uma prática, no caso a dança, isso evidencia que as pesquisas recentes estão atentas às demandas tecnológicas em suas potencialidades de ensino e aprendizagem dos fenômenos e conteúdos culturais e artísticos (des)contínuos. Conforme explica Kenski em O Novo Ritmo da Informação (2012), a tecnologia digital transformou o modo de pensar e apreender os fenômenos do mundo:

A tecnologia digital rompe com as formas narrativas circulares e repetidas da oralidade e com o encaminhamento contínuo e sequencial da escrita e se apresenta como um fenômeno descontínuo, fragmentado e, ao mesmo tempo, dinâmico, aberto e veloz. Deixa de lado a estrutura serial e hierárquica na articulação dos conhecimentos e se abre para o estabelecimento de novas relações entre conteúdos, espaços, tempos e pessoas diferentes (KENSKI, 2012, p. 32).

Com a mediação das tecnologias digitais, as pessoas estão se relacionando cada vez mais rápido e se comunicando mais frequentemente. Com as novas conexões cibernéticas, ocorre uma acentuada interação entre distintas pessoas em diversas organizações e/ou redes sociais, de acordo com Santaella (2013). Toda essa conectividade tem provocado mudanças substanciais na forma de ensinar e de aprender e, neste sentido, segundo Coll e Monereo (2010, p. 39), "as paredes dos 
estabelecimentos escolares [admitimos aqui as universidades também] tendem a tornar-se difusas".

\section{Em Comunicação Ubíqua: representações na cultura e na educação (2013),} Santaella afirma que os modos alternativos de relacionamento professor-interagente/ aluno, estão cada vez mais ubíquos e digitalizados. Werthein e Cunha (2000), por sua vez, argumentam que é fundamental o uso das tecnologias digitais no ambiente educativo. Logo, destacamos que o processo de ensino-aprendizagem, na atualidade, já ocorre também em espaços e tempos fora da sala de aula e, para tanto, as ferramentas didáticas precisam se apoiar em atividades cada vez mais dinâmicas, adaptativas e flexíveis, possibilidades estas que o universo digital amplia exponencialmente.

É neste contexto que a proposta de EaD em dança se configura como uma possibilidade ancorada em perspectivas e expectativas evidenciadas há algum tempo no universo da educação tecnológica ampliada.

Machado (2018) defende que, para um processo efetivo de ensinoaprendizagem, não necessariamente docentes e discentes devam estar conectados presencialmente de forma física e síncrona, mas afirma também que há a necessidade da preparação prévia de uma equipe envolvida no desenvolvimento de possibilidades adequadas ao ensino semipresencial, a execução e a mediação de todas as etapas do processo.

Como explica Tardif (2014), diante da pedagogia e do ponto de vista do trabalho docente, a tecnologia constitui e faz parte da atividade dos professores. Em outras palavras, a tecnologia é atuante e ativa no próprio trabalho docente e, como o professor é o ator de sua pedagogia, a qual dá corpo e sentido à troca de conhecimentos com o aluno a partir do saber do seu próprio trabalho, o aluno responde e atua com essa tecnologia de forma integrada e inclusiva.

A recomendação de modalidades de EaD que propomos para os cursos de licenciatura em dança traz em seu âmago a possibilidade de construir pontes entre o 
ensino co(rpo)presencial e o ensino virtual. Nesta última possibilidade, entrariam em destaque, sobretudo, as disciplinas ditas reflexivas das grades curriculares das graduações. $O$ apoio que as metodologias (inter)ativas poderiam trazer para essas aulas teóricas seria essencial na (re)formulação de aprendizagem com a utilização de mediação tecnológica digital à distância (MATTAR, 2017). O modelo de sala de aula invertida, por exemplo, no qual o aluno/sujeito autônomo da aprendizagem traz o conteúdo já estudado para se discutir, analisar e experimentar nas aulas, pode ser utilizado neste sistema, e o professor/tutor pode ter acesso e mediar o uso de vídeos gravados, teleconferências e realidade virtual (avatares) para dispor o conteúdo em um formato digital (MOTTA, 2018), complementando [e não substituindo], a modalidade co(rpo)presencial das atividades de criação e prática dançante.

Já os conteúdos de abordagens e lógicas de dança deverão ser explorados de forma imersiva, alternando momentos de vivência mais prolongados, concentrados e plurais, experiência, com trocas singulares do entendimento do corpo para determinadas propostas e a aplicabilidade do conteúdo que emerge da necessidade da junção de teoria e prática em seu formato que aqui denominamos $\mathrm{co}(\mathrm{rpo})$ presencial complementado pela experiência à distância.

Para que esse percurso de educação híbrida venha a se desenvolver de modo concreto, Fava (2016) salienta que não basta apenas modernizar a instituição/curso e dar-Ihe condições tecnológicas, como, por exemplo, computadores e tablets da última geração. É imprescindível proporcionar a todos os saberes necessários e o letramento nessas ferramentas tecnológicas e suas lógicas, as quais, como ressalta Santaella (2013), são diferentes das praticadas no universo analógico. No contexto social da era digital, Santaella (2013) destaca que o dom da ubiquidade - o poder estar em todos os lugares diferentes ao mesmo tempo - é compartilhado a partir das potencialidades da internet, que permite, por exemplo, ao mesmo indivíduo ouvir o professor em uma sala de aula física e postar conteúdos relacionados nas redes sociais digitais ao mesmo tempo. Isso torna complexas as relações de ensino e aprendizagem, bem como amplia as condições de produção, circulação e recepção de conteúdos. 
Mattar (2017), sugere que o ensino baseado em problemas (PBL) pode gerar a apropriação de um determinado caso (entendemos aqui como uma tarefa de pesquisa, criação de movimentos, sequências motoras, investigação a partir de uma proposição temática) que pode ser exposto aos alunos conectados online e esses, por meio das respostas motoras de seus corpos tentam resolver o problema gerado ou apresentado, estando a praticar estes movimentos em ambientes diferentes daquele onde se insere o professor/tutor/mediador da proposição ou tarefa/problema. Esse problema pode ser verbal, corporal e/ou sinestésico e poderá vir a gerar oportunidades inusitadas de aprendizagem.

Em Tecnologias do tempo presente (2013), Kenski apropria-se de um otimismo no que diz respeito às incursões tecnológicas no campo da Educação. Para essa autora, as tecnologias devem ser compreendidas como geradoras de oportunidades de aprendizagem, quando docentes/tutores passam a utilizar aparatos tecnológicos e metodologias, como a EaD, no intuito de expandir as capacidades sensoriais, cognitivas e motoras do ser humano/sujeito da aprendizagem. Ressaltamos que esta modalidade pode propiciar uma ampla e eficaz comunicação entre professor/ tutor e aluno/sujeito da aprendizagem, uma vez que ela se torna mais colaborativa e menos centralizada na figura tradicionalista do docente. Além destas prerrogativas, mencionamos as oportunidades reais de ampliação do acesso ao conhecimento diante da extensão territorial no Brasil e do pouco número de instituições universitárias capacitadas a formar os profissionais da educação em artes/dança pelo sistema unicamente presencial.

Não estamos asseverando que as tecnologias de aprendizagem e as modalidades de EaD tornar-se-ão substitutas da docência co(rpo)presencial. Ao contrário, manifestamos nosso posicionamento reflexivo de acordo com a problematização encontrada em Fava (2016, p. 288):

[...] à medida que os computadores se transfigurarem em máquinas 'inteligentes' cada vez mais potentes, não serão substitutos dos seres humanos, e sim complementos. Isso significa que as escolas mais 
valiosas, influentes, benéficas das próximas décadas serão as que fortalecerem seus educadores, não as que tentarem torná-los obsoletos.

Desse modo, atestamos que o corpo docente pertencente às instituições de ensino superior e responsável pela formação de artistas-docentes na/da dança, necessita estar preparado para lidar com as ferramentas tecnológicas atuais, porque, como se vê, elas colaboram na efetivação de determinados resultados, muitas vezes mais rápidos e eficientes do que o esperado. Neste processo ou proposição metodológica, o docente não está desacompanhado; os próprios alunos estão imersos e vivenciam, o tempo todo, essa 'era digital ubíqua', conforme expõe Santaella (2013):

Para isso, antes de tudo, é preciso viver as tecnologias. Se vamos falar de tecnologias, temos que estar nelas, e não simplesmente mirá-las com arrogância do ponto de vista aéreo de um escritório. Temos que nos inteirar não apenas dos traços mais evidentes que gritam na ponta do iceberg, mas constantemente medir a sua temperatura submersa. Esta pode estar gestando transformações que ainda não aparecem na superfície (SANTAELLA, 2013, p. 21).

Se na educação contemporânea, como afirma Santaella (2013, p. 322), "as mídias são o tema e o objeto da educação", Mattar (2013) complementa que, além das mídias, os alunos necessitam, logo, do trabalho ou ensino bilateral que envolve o duplo engajamento tecnológico: professor e aluno. Reiteramos que os docentes não podem se afastar das tecnologias (inter)ativas, porque os jovens universitários estão cada vez mais próximos delas, assumindo-as como uma segunda linguagem comunicacional.

Os estudos e as pesquisas de Prenski (2001) e Mattar (2013) em muito embasam nossas reflexões sobre este tópico, visto que ambos explicam que existem diversos estilos de aprendizagem nas novas gerações, principalmente aquelas nascidas em meio aos computadores, às potencialidades da internet, à popularização dos smartphones e a tantos outros recursos digitais. Afirmam os autores, que os nativos digitais são jovens que já nasceram imersos na cibercultura e, por isso, veem as mídias digitais e seus recursos com naturalidade, diferentemente de seus professores que, como imigrantes digitais (nascidos antes da expansão da internet e de 
seus aparatos em rede), percebem muitas vezes as tecnologias, especialmente as digitais, como ameaçadoras de um pensar-fazer artesanal/analógico.

Kenski (2012), ao citar a história e os avanços tecnológicos que o professor utiliza para construir e mediar seu fazer dentro da sala de aula, demonstra que esta 'ameaça', na verdade, é infundada visto que os equipamentos técnicos sempre foram auxiliadores das práticas pedagógicas. Motta (2018) ao fazer referência a Kenski (2012; 2013), relembra que o PowerPoint, hoje substituído pelo software Prezi, é um dos recursos que mais auxiliam a sequência didática das aulas, tanto como material de apoio para a exposição oral do professor quanto como material de consulta para o aluno. Como notamos, o uso de recursos digitais em sala de aula, não está fora da atuação do professor, nem como substituto dele, mas mais como uma ferramenta facilitadora do processo de aprendizagem.

De acordo com Bates, em sua obra Educar na era digital: design, ensino e aprendizagem (2017):

não devemos apenas olhar para as características técnicas de uma tecnologia, nem o sistema mais amplo de tecnologias em que ela está localizada, nem mesmo as crenças educacionais que trazemos como professores de sala de aula. Precisamos também examinar as características específicas das diferentes mídias em relação a seus formatos, sistemas de símbolos e valores culturais. Essas características específicas são, cada vez mais, denominadas potencialidades (affordances) das mídias ou tecnologias (BATES, 2017, p. 267).

A partir de Bates (2017), apreendemos que uma das principais potencialidades de uma modalidade educacional como a EaD é a compreensão das características específicas que essa metodologia (inter)ativa traz, agregando, facilitando ou até modificando o modus operandi de uma prática educativa forjada na co(rpo)presencialidade. Assimilamos, assim, a conveniência e a relevância do provimento imediato de oportunidades de aprendizagem amplas e alternativas aos universitários, principalmente os ingressantes nos cursos de licenciatura em dança, 
uma vez que os grupos sociais que ingressam no ensino superior, principalmente no contexto brasileiro, possuem diversas e distintas habilidades e competências digitais. Bates afirma que:

talvez ainda mais importante seja a ideia de que muitas mídias são melhores do que uma. Isso permite que os alunos com diferentes preferências de aprendizagem sejam contemplados e permite que o assunto seja ensinado de formas diferentes por diferentes meios, levando assim a uma compreensão mais profunda ou a uma ampla gama de habilidades no uso do conteúdo (BATES, 2017, p. 267).

Obviamente, não estamos apartados das considerações que envolvem, por parte das instituições de ensino superior, considerável aumento de custos derivados do investimento em tecnologias digitais para suprir as demandas da EaD e demais aplicativos e softwares. Todavia, existem alternativas gratuitas e que possuem funcionalidades semelhantes, porém específicas para determinados trabalhos e/ou produtos. Um fator importante para corroborar nossa proposição argumentativa de que é preciso ampliar a oferta de diferentes mídias e recursos tecnológicos para os alunos dos cursos de licenciatura em dança no país é que, ao se efetivar estas possíveis ações - descentralização, transformação e inclusão - da EaD, esse processo desencadeará uma maior individualização e personalização da aprendizagem.

Como sustentam Mattar (2017) e Bates (2017), isso favorece a organização do ensino, porque, com as novas mídias e seus recursos, o professor consegue atender melhor os alunos com estilos e necessidades especiais e/ou diferentes tipos de aprendizagem. Em outras palavras, a ação tecnológica da EaD acaba por gerar uma educação transformadora e inclusiva, cujas motivações gravitam em torno da cultura digital, porque nesta modalidade usufrui-se das tecnologias digitais e móveis como uma extensão da aprendizagem, inclusive na construção do saber pedagógico entre professor, objeto de saber e aluno.

Adotamos como conceito de cultura digital o que estabelece Santaella (2013, p. 234), ou seja: "uma cultura descentralizada, reticulada, baseada em módulos autônomos. Materializa-se em estruturas de informação que veiculam signos 
evanescentes, voláteis, líquidos, mas recuperáveis a qualquer instante". Em contextos de cultura descentralizada, a aprendizagem por meio da tecnologia digital e móvel possibilita, em diversos casos, estudar e assimilar os conteúdos até quando se está percorrendo longos caminhos - em ônibus, trens, carros - como passageiros e com maior facilidade, diferenciando-se dos estudos efetuados unicamente com livros e cadernos físicos. A aprendizagem pode ser híbrida/blended e ampliar a sua eficácia e abrangência.

Argumentos postulados por Horn, Staker, Christensen (2015) e Mattar (2017), atestam que a aprendizagem híbrida, na qual interagem diferentes e diversos recursos tecnológicos e midiáticos, tanto na modalidade de EaD quanto na presencial, deve ser estimulada na educação contemporânea ubíqua. Observamos que a Organização das Nações Unidas para a Educação, a Ciência e a Cultura (UNESCO, 2009) recomenda a construção, em larga escala, de comunidades (ou ilhas) de aprendizagem nas quais os alunos se inter-relacionam, ao mesmo tempo em que se pretende dar um suporte in loco para a referida aprendizagem. Com isso, o acesso não seria mais o principal desafio, pois, quando se sofisticam os recursos pedagógicos a partir dos recursos tecnológicos, os espaços se encurtam e o processo de ensino e aprendizagem é dinamizado. Com isso, fundamenta-se, no que se refere ao uso das mídias e das tecnologias, que as novas mídias não substituem ou excluem as anteriores, como Bates (2017) discute:

enquanto novas tecnologias são desenvolvidas e incorporadas aos sistemas de mídia, velhos formatos e abordagens são trazidos das velhas para as novas mídias. A educação não é exceção. A nova tecnologia é "acomodada" a velhos formatos, como clickers e captura de aulas, ou tentamos criar a sala de aula no espaço virtual, como no caso dos ambientes virtuais de aprendizagem. No entanto, novos formatos, sistemas simbólicos e estruturas organizacionais que explorem as características específicas da internet como uma mídia estão sendo descobertos gradualmente (BATES, 2017, p. 268).

No contexto da educação global, a UNESCO também recomenda a implementação de políticas públicas que possam instituir o aprendizado móvel, criando, assim, uma importância e uma conscientização sobre a validade dessa proposta. Um 
exemplo disso seria a expansão de banda larga para todos e a valorização da formação de professores/tutores de forma continuada. Essa proposta, a médio e a longo prazos, promoveria uma maior troca de informações entre os usuários, incutindo e fomentando de forma mais sustentável as práticas e os usos dos recursos digitais no dia a dia dos cidadãos. Sobre o uso e o acesso das tecnologias digitais da informação e comunicação (TDIC) e da internet em variados ambientes de aprendizagem, Coll e Monereo (2010) justificam também que:

as TIC em geral, e a internet em particular, proporcionam uma excelente oportunidade para se saltar em direção a uma educação de mais qualidade, baseada em princípios de solidariedade e igualdade [grifo nosso]. Contudo, se esse salto não for bem dimensionado, se não partimos das diferentes realidades sociais e educacionais, com suas conquistas e suas carências, podemos acabar dando um salto no vazio e o avanço educacional esperado pode acabar não passando de mais uma operação econômica e comercial (COLL; MONEREO, 2010, p. 43).

Neste contexto, o professor/tutor, como um ser intermediador, motivador e curador do saber, também encontra dificuldades em manipular, gerir e conduzir seu ensino e aprendizagem referente à utilização da tecnologia, desde um simples comando no computador e/ou até mesmo o entendimento e a apropriação de alguns recursos que estão ocultos em seus softwares, ou por eles desconhecidos. Esse profissional pode se sentir perdido e até confuso diante das diversas possibilidades que as tecnologias proporcionam. Como se pode apreender, o papel do professor mudou.

\section{CONSIDERAÇÕES FINAIS}

Neste artigo, refletimos sobre a possibilidade de uma educação tecnológica e híbrida/blended como contributo para a formação de artistas-docentes no âmbito das licenciaturas em dança no Brasil. $O$ foco de nossa investigação recaiu sobre a proposta de Ensino a Distância como uma estratégia metodológica que rompe o espaço físico da sala da aula e o estende por espaços ampliados de ensino-aprendizagem mediado, o que acaba por romper o paradigma da aprendizagem e da prática da dança unicamente de forma co(rpo)presencial e artesanal. 
A partir de uma ampla discussão sobre a possibilidade desafiadora da EaD, com seus meios/instrumentos comunicacionais ubíquos na relativização de espaços geográficos, na convocação de ações tecnológicas transformadoras e inclusivas, destacamos esta metodologia de ensino-aprendizagem como uma prática pedagógica colaborativa urgente e necessária em meio a um contexto tecnológico.

Compreendendo esse contexto, o desafio da educação brasileira no âmbito do ensino universitário e, particularmente nas licenciaturas em dança, objeto de nossa investigação, é articular mudanças sociais e políticas às transformações tecnológicas. A formação e a atualização/instrumentalização dos docentes quanto aos requisitos da educação mediada por tecnologias, neste contexto, deve ser constante. Para tal intento, torna-se necessário atualizar e disponibilizar novas estruturas para o processo interativo de ensino-aprendizagem, que hoje caminha para um outro patamar educacional mais digital, híbrido/blended e ubíquo, conforme apontam os estudos de Mattar (2017), Bates (2017) e Santaella (2013), trazidos ao presente trabalho, entre outros autores, como ancoragem teórica principal.

Aos docentes, cabe a atualização constante quanto ao uso de ferramentas tecnológicas e de práticas de modalidades de ensino bilateral, híbrido e mediado por computadores.

Finalmente, este estudo de caráter reflexivo e de ampla revisão bibliográfica narrativa, além da análise de documentos legais de educação, possibilitou que compreendêssemos que a proposição da modalidade pedagógica da EaD na formação dos profissionais da educação em Artes/Dança configura-se como um instrumento estratégico afinado aos pressupostos de um contexto tecnológico e digital contemporâneo.

Frente aos desafios de uma possível Educação a Distância, seguimos ancorados no otimismo de que se efetivem, de fato, as oportunidades cada vez mais transformadoras e inclusivas na implantação de um processo que provoque e amplie as relações do ensino-aprendizagem da dança aqui, ali e em todo o lugar. 


\section{REFERÊNCIAS}

BATES, T. Educar na era digital: design, ensino e aprendizagem. Tradução João Mattar. São Paulo: Artesanato Educacional, 2017.

BRASIL. Lei de Diretrizes e Bases da Educação Nacional. Lei número 9394, 20 de dezembro de 1996.

BRASIL. Portaria $\mathbf{n}^{\circ}$ 4.059, de 10 de dezembro de 2004, Disponível em: http:// portal.mec.gov.br/sesu/arquivos/pdf/nova/acs_portaria4059.pdf. Acesso em: 21 jul. 2018.

COLL, C; MONEREO, C. Psicologia da educação virtual: aprender e ensinar com as tecnologias da informação e comunicação. Porto Alegre: Artmed, 2010.

CONSELHO NACIONAL DE EDUCAÇÃO. Diretrizes Curriculares Nacionais para os cursos de graduação em dança. Resolução $n^{\circ} 3$, de 8 de março de 2004. Disponível em: http:// portal.mec.gov.br/cne/arquivos/pdf/CES03-04.pdf. Acesso em: 21 jul. 2018.

CUNHA, M. H. Aprendizagem colaborativa: a educação à distância como ferramenta de difusão de conhecimento, 2016. Disponível em: http:// inspirebr.com.br/uploads/midiateca/ 63aff6bf732aca1c6c8c22a44314e685.pdf. Acesso em: 21 out. 2018.

FAVA, R. Educação para o século XXI: a era do indivíduo digital. São Paulo: Saraiva, 2016.

GRINSPUN, M. P. S. Z. Os novos paradigmas em educação: os caminhos viáveis para uma análise. Revista Brasileira de Estudos Pedagógicos, Brasília, v. 75, n. 179-80-81, 2007. Disponível em: http://rbep.inep.gov.br/index.php/rbep/article/view/ 1155/1129. Acesso em: 21 dez. 2018.

HORN, M.; STAKER, H.; CHRISTENSEN, C. Blended: usando a inovação disruptiva para aprimorar a educação. Tradução de Maria Cristina Gularte Monteiro. Porto Alegre: Penso, 2015.

INEP. Censo da Educação Superior. Disponível em: http://portal.inep.gov.br/ censo-daeducacao-superior. Acesso em: 21 set. 2018.

KENSKI, V. M. O novo ritmo da informação. 8. ed. Campinas, SP: Papirus, 2012.

KENSKI, V. Tecnologias e tempo docente. Campinas, SP: Papirus, 2013.

MACHADO, N. S. Fazendo o semipresencial e sonhando com o ensino híbrido na graduação, a voz dos estudantes: uma análise comparativa de modelos pedagógicos nos cenários público e privado. 2018. 150 f. Dissertação (Mestrado em Educação e Novas Tecnologias) - Centro Universitário Internacional (UNINTER), Curitiba, 2018.

MARQUES, I. Dança no contexto: uma proposta para a educação contemporânea. 150 f. Tese de Doutorado. Faculdade de Educação, Universidade de São Paulo (USP), São Paulo, 1996.

MARQUES, I. Ensino de dança hoje: textos e contextos. 4. ed. São Paulo: 2007.

MARTINS, G.A.; PINTO, R.L. Manual para elaboração de trabalhos acadêmicos. São Paulo: Atlas, 2001. 
MATTAR, J. Guia de educação à distância. São Paulo: Cengage Learning: Portal da Educação, 2011.

MATTAR, J. Metodologias Ativas: para educação presencial, Blended e a distância. 1. ed. São Paulo: Artesanato Educacional, 2017.

MATTAR, J. Aprendizagem em ambientes virtuais: teorias, conectivismo e MOOCs. Revista Teccogs, n. 7, 2013, p. 20 - 40. Disponível em: http://www4.pucsp.br/ pos/tidd/teccogs/ edicao_completa/teccogs_cognicao_informacao-edicao_7-2013-completa.pdf. Acesso em: 21 out. $20 \overline{1} 8$.

MENICACCI, A. O ensino da dança frente às tecnologias: algumas reflexões. In: WOSNIAK, Cristiane; MEYER, Sandra; NORA, Sigrid (orgs.). Seminários de dança: o que quer e o que pode [ser]a técnica? Joinville: Letrad'água, 2009, p. 99-106.

MOTTA, E. L. O. Dança e tecnologia: entre ensino e prática docente. 2018. 140 f. Dissertação (Mestrado em Educação e Novas Tecnologias) - Centro Universitário Internacional (UNINTER), Curitiba, 2018.

MORÁN, J. Mudando a educação com metodologias ativas. In: SOUZA, Carolos Alberto; MORALES, Ofélia Elisa Torres (orgs.). Coleção Mídias Contemporâneas. Convergências Midiáticas, Educação e Cidadania: aproximações jovens. Vol. II, PROEX/UEPG, 2015. Disponível em: http://www2.eca.usp.br/moran/wpcontent/ uploads/2013/12/ mudando_moran.pdf. Acesso em: 21 nov. 2018.

PEÑA, M. I. D.; ALVES, M. R.; PEPPE, M. A. Educação, tecnologia e humanização. Cad. de Pós-Graduação em Educação, Arte e História da Cultura. São Paulo, v. 3, n. 1, p. 9-19, 2003. Disponível em: http://www.mackenzie.com.br/fileadmin/ Pos_Graduacao/Mestrado/ Educacao_Arte_e_Historia_da_Cultura/Publicacoes/Volume3/

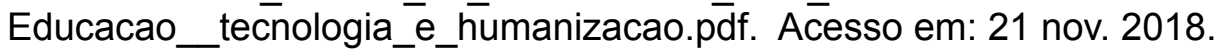

PPC - Projeto Político Pedagógico de Curso: Curso de Bacharelado e Licenciatura em Dança - Universidade Estadual do Paraná - campus de Curitiba II (FAP), 2017.

PRENSKY, M. Digital Natives, Digital Immigrants, Part 1. On the Horizon, v. 9, n. 5, 2001, p. 1-6.

SANTAELLA, L. Culturas e artes do pós-humano: da cultura das mídias à cibercultura. São Paulo: Paulus, 2003.

SANTAELLA, L. Comunicação ubíqua: representações na cultura e na educação. São Paulo: Paulus, 2013.

SILVA, E. R. Graduação em Dança no Brasil: professor como orientador e aluno como protagonista. In: ROCHA, Thereza (org.). Graduações em dança no Brasil: o que será que será? Joinville: Nova Letra, 2016, p. 29-36. Disponível em: http://www.ifdj.com.br/site/wpcontent/uploads/2016/07/IX-Seminarios-de-Danca-Graduacoes-em-Danca-no-Brasil_VariosAutores.pdf. Acesso em: 21 jan. 2019.

TARDIF, M. Saberes docentes e formação profissional. 17. ed. Petropólis-RJ: Vozes, 2014. 


\section{EDUCACÃO, ARTES E INCLUSÃO}

UNESCO. Educação e aprendizagem para todos: olhares dos cinco continentes - Brasília: Ministério da Educação, 2009.

WERTHEIN, J; DA CUNHA, C. Fundamentos da nova educação. Unesco, 2000.

WOSNIAK, C. A universidade e a formação do artista docente da(na) dança. 0 Teatro Transcende. CCEAL /FURB. Blumenau, V. 22, N. 1-2, 2017, p. 1-16. Disponível em: http:// proxy.furb.br/ojs/index.php/oteatrotranscende/article/view/ 6951/3712. Acesso em: 21 jan. 2019.

Recebido em 19 de fevereiro de 2019

Aprovado em 27 de março de 2020 